\title{
Closed Reduction and Hip Spica for Treatment of Developmental Dysplasia of the Hip in Children
}

\author{
Mutasem Aldhoon*, Ghandi Almanasir, Ala Al-Qudah, Ashraf Otoum and Deya'deen Alrashdan \\ MD, Orthopedic Surgeon, Royal Medical Services, Jordan
}

Submission: October 04, 2021; Published: October 19, 2021

*Corresponding author: Mutasem Aldhoon, MD, Pediatric Orthopedic Surgeon, Queen Rania Hospital for Children, King Abdullah II Street, Amman, Jordan

\section{Abstract}

Objectives: This retrospective study aims to determine the results of treatment of patients with developmental dysplasia of the hip (DDH (by closed reduction (CR) and hip spica and analyze the risk factors for the associated complications of this procedure.

Methods: A retrospective review of all patients treated by CR and hip spica from January 2014 to January 2019 in Queen Rania Hospital for Children was done. The operation was considered successful if we could obtain and maintain concentric and stable reduction depending on postoperative CT scan and last radiographic follow-up. The incidence of residual acetabular dysplasia on final follow-up was assessed as well.

Results: A total of 202 patients (292 hips) who underwent CR and hip spica for DDH were evaluated with a median follow-up of 25.4 months. The initial success of CR documented by postoperative CT scan was seen in 178 patients (88.1\%). Of these, 170 patients (95.5\%) continued to have satisfactory reduction as documented by the last follow-up radiograph. Residual dysplasia was seen in 172 hips (68.5\%) at the final followup.

Conclusion: CR and hip spica could achieve a stable and concentric reduction in most patients. However, this procedure is associated with a high rate of residual acetabular dysplasia. We recommended that the parents of such patients be counseled about the possibility of further surgery at a later stage.

Keywords: Developmental Dysplasia of the Hip; Closed Reduction; Hip Spica; Residual Dysplasia

\section{Introduction}

Developmental dysplasia of the hip (DDH) is one of the most common pediatric orthopedic conditions seen in orthopedic clinics [1]. Treatment varies from conservative methods such as Pavlik harness or abduction splints to advanced surgeries with open reduction and acetabular/femoral osteotomies [1-4]. The treatment aims to achieve a stable, concentric reduction to facilitate normal hip and acetabular growth. For those infants who fail initial conservative management or those who present late, treatment often starts with closed reduction (CR) and hip spica. Although this procedure is generally safe and successful, the risk for iatrogenic avascular necrosis (AVN) of the femoral head is a significant concern [4-6]. Other problems include redislocation in spica and the need for secondary surgery to address residual acetabular dysplasia [5,6]. Due to the mixed results of this procedure and the long-term negative impact of femoral head AVN, the role of CR and hip spica in the management of DDH is increasingly being questioned [7-10]. The purpose of this retrospective study is to determine the success rate when immobilization was done in $100^{\circ}$ of hip flexion and $45^{\circ}$ of abduction with a strict commitment to these limits.

\section{Methods}

After institutional ethical committee approval was obtained, data of all patients who underwent CR and hip spica in Queen Rania Hospital for Children / Royal Medical Services for children were reviewed retrospectively. All hips were frankly dislocated by radiograph (International Hip Dysplasia Institute (IHDI) grade 3 or 4) at the time of CR and hip spica. Bilateral hips were counted separately. Failure of CR (unsuccessful procedure) was defined as either dislocation in immediate postoperative CT scan or at most recent radiographic follow-up. Residual dysplasia was defined as Acetabular Index $(\mathrm{AI})>25^{\circ}$. Descriptive analysis with the mean and standard deviation was applied to continuous variables, while for categorical variables, frequencies and percentages were considered. The bivariate ( $\chi 2$-test) of independence was used to assess the correlations between the patients' categorically 


\section{Orthopedics and Rheumatology Open Access Journal (OROAJ)}

measured variables with their risk of high residual dysplasia for both hips, each hip separately. The unpaired samples t-test was applied to assess the statistical significance of mean differences on continuous variables across the levels of the binary variables, i.e., the risk of residual dysplasia. The multivariate logistic binary regression analysis was used to assess the predictors' statistical significance for the hip displacement patients' odds of having had a high right and left residual hip dysplasia despite the completed hip reduction. The association between predictors with the patient's residual dysplasia risk was expressed as an Odds Ratio (OR) with a 95\% Confidence Interval. The SPSS IBM V21 commercially available statistical data analysis program was used, and the alpha significance level was considered at 0.050 level.

\section{Surgical Technique}

All procedures were performed under general anesthesia. Examination under anesthesia was done routinely to evaluate the reducibility and stability of the dislocated hip. Percutaneous adductor tenotomy was performed for clinically unstable hips with soft-tissue contracture and limited abduction. While one surgeon gently reduced the hip and reduced the safe position ( $45^{\circ}$ abduction, $100^{\circ}$ flexion,) the other surgeon applied a double hip spica. All patients underwent postoperative selected cuts pelvic CT scan to confirm the reduction. Once reduction is established, the patient was given a clinic appointment in 6 weeks to reevaluate reduction and spica. Then we continued the treatment for another six weeks in the same spica to complete 12 weeks of hip spica treatment. After removing the hip spica, we routinely prescribed an abduction splint for another 12 weeks to maintain the reduction and conclude the treatment.

\section{Results}

A total of 202 patients (292 hips) who underwent CR and hip spica for DDH were reviewed retrospectively. The sociodemographic characteristics and outcomes were collected and analyzed (Table 1). The median age at initial CR was 7.63 months (range, 5 to 10 months). Of these, 24 patients (11.9\%) could not be successfully reduced on the initial attempt of CR. Table 2 describes the analysis findings based on the treatment and the resulting outcomes from the various treatments/interventions. Our data showed that $36.6 \%$ of patients presented with left unilateral DDH, $18.8 \%$ of the children had right unilateral DDH, and $44.6 \%$ of the children had bilateral DDH. In addition, $72.8 \%$ of the patients had applied Pavlik harness at some stage, and $63.9 \%$ had been treated with adductor tenotomy. The chi-squared test of independence showed that $98(66.7 \%)$ of the patients treated with Pavlik harness $(n=129)$ required a tenotomy. However, there was no statistically significant association between the use of the Pavlik harness and tenotomy ( $\chi 2(1)=1.84, \mathrm{p}-0.174)$.

Table 1: Descriptive analysis of the patients sociodemographic. $\mathrm{N}=2$.

\begin{tabular}{|c|c|c|}
\hline & Frequency & Percentage \\
\hline Sex & & \\
\hline Female & 173 & 85.6 \\
\hline Male & 29 & 14.4 \\
\hline Age (months) at surgical time & & $7.63(1.70)$ \\
\hline Age group & & \\
\hline$<=7$ months & 93 & 46 \\
\hline$>7$ Months & 109 & 54 \\
\hline & &
\end{tabular}

Table 2: The descriptive analysis of the patients displaced hip, received treatments and outcomes from treatment. N=202.

\begin{tabular}{|c|c|c|}
\hline & Frequency & Percentage \\
\hline \multicolumn{3}{|l|}{ Affected hip side } \\
\hline Left & 74 & 36.6 \\
\hline Right & 38 & 18.8 \\
\hline Bilateral & 90 & 44.6 \\
\hline \multicolumn{3}{|l|}{ Received Pelvic Harness therapy } \\
\hline No & 55 & 27.2 \\
\hline Yes & 147 & 72.8 \\
\hline \multicolumn{3}{|l|}{ Required Adductor Tenotomy } \\
\hline No & 73 & 36.1 \\
\hline Yes & 129 & 63.9 \\
\hline \multicolumn{3}{|l|}{ Initial Success of CR documented by CT scan } \\
\hline No & 24 & 11.9 \\
\hline Yes & 178 & 88.1 \\
\hline \multicolumn{3}{|l|}{ Final Success of CR documented by X-ray } \\
\hline No & 7 & 3.9 \\
\hline Yes & 171 & 96.1 \\
\hline Final Right acetabular Index (degrees), Mean (SD) & & $27.03(5.22)$ \\
\hline Right Hip acetabular angle & & \\
\hline
\end{tabular}




\section{Orthopedics and Rheumatology Open Access Journal (OROAJ)}

\begin{tabular}{|c|c|c|}
\hline$<=25$ degrees & 45 & 41.7 \\
\hline$>25$ degrees & 63 & $27.34(3.79)$ \\
\hline Final Left acetabular Index (degrees), Mean (SD) & & \\
\hline Left Hip acetabular angle & & 23.8 \\
\hline$<=25$ degrees & 34 & 76.2 \\
\hline$>25$ Degrees & 109 & $25.40(15.11)$ \\
\hline Follow up time (months), mean (SD) & & \\
\hline
\end{tabular}

The initial success of CR documented by postoperative CT scan was seen in 178 patients (88.1\%). Of these, 170 patients (95.5\%) continued to have satisfactory reduction as documented by data, treatments received, and the final acetabular index the last follow-up radiograph. Eight patients (4.5\%) failed to maintain a stable and concentric reduction at the final follow-up radiograph. The AI was measured on AP pelvic radiographs at the final follow-up radiograph. Residual dysplasia was defined as AI > $25^{\circ}$ as this value is predicted for later acetabuloplasty [11,12]. The results showed that the mean acetabular index measurements for the right hip were 27.03 degrees $(S D=5.22)$. For the left hip (27.64 degrees, $\mathrm{SD}=3.79$ ), it was found that $5.3 \%$ of patients had residual dysplasia on the right side, and $76.2 \%$ patients had residual dysplasia on the left side.

We studied the association between patient sociodemographic measurements. The bivariant and multivariant analyses were used, and the finding for each hip was analyzed separately. The results are shown in Table 3A \& 3B, Table 4A \& 4B. The analysis results showed that the patient's sex, age, age group, and use of Pavlik harness therapy did not converge significantly on their likelihood of having acetabular index value above 25 degrees. However, another chi-squared test of independence suggested that the patients who operated after seven months of age were slightly less predictable for higher left hip acetabular index than patients managed at a younger age $(p=0.083)$. The final success of any treatment did not correlate significantly with their measured acetabular index levels ( $p>0.050)$ for both hips.

Table 3A: Bivariate Analysis of the patient's high right hip acetabular index post-surgery. $\mathrm{N}=115$

\begin{tabular}{|c|c|c|c|c|}
\hline \multicolumn{5}{|c|}{ Right Hip Acetabular Index } \\
\hline & $<=25$ degrees, $n=49$ & $>25$ degrees, $n=66$ & Test Statistic & p-value \\
\hline \multicolumn{5}{|l|}{ Sex } \\
\hline Female & $43(87.8)$ & $56(84.8)$ & $\chi 2(1)=0.20$ & 0.656 \\
\hline Male & $6(12.2)$ & $10(15.2)$ & & \\
\hline Age (months) at surgical time & & & $t(106)=0.60$ & 0.552 \\
\hline \multicolumn{5}{|l|}{ Age group } \\
\hline$<=7$ months & $21(42.9)$ & $33(50)$ & $\chi 2(1)=0.58$ & 0.448 \\
\hline$>7$ Months & $28(57.1)$ & $33(50)$ & & \\
\hline \multicolumn{5}{|l|}{ Affected hip side } \\
\hline Unilateral-Right & $9(18.4)$ & $27(40.9)$ & $\chi 2(1)=6.65$ & 0.010 \\
\hline Bilateral & $40(81.6)$ & $39(59.1)$ & & \\
\hline \multicolumn{5}{|l|}{ Received Pelvic Harness therapy } \\
\hline No & $14(28.6)$ & $19(28.8)$ & $\chi 2(1)=0.001$ & 0.98 \\
\hline Yes & $35(71.4)$ & $47(71.2)$ & & \\
\hline \multicolumn{5}{|l|}{ Required Tenotomy surgery } \\
\hline No & $11(22.4)$ & $27(40.9)$ & $\chi 2(1)=4.33$ & 0.037 \\
\hline Yes & $38(77.6)$ & $39(59.1)$ & & \\
\hline \multicolumn{5}{|l|}{ Final Success of CR documented by X-ray } \\
\hline No & $5(10.2)$ & $1(1.5)$ & $\chi 2(1)=2.65$ & 0.104 \\
\hline Yes & $44(89.8)$ & $64(98.5)$ & & \\
\hline \multicolumn{5}{|l|}{$\begin{array}{l}\text { Final Left acetabular Index (degrees), } \\
\text { Mean (SD) Left Hip acetabular angle }\end{array}$} \\
\hline$<=25$ degrees & $16(40)$ & $8(20.5)$ & $\chi 2(1)=3.55$ & 0.06 \\
\hline$>25$ Degrees & $24(60)$ & $31(79.5)$ & & \\
\hline Follow up duration (months), mean & & 28.62 & & \\
\hline (SD) & $21.88(15.75)$ & $(14.25)$ & $t(97.5)=2.40$ & 0.020 \\
\hline
\end{tabular}




\section{Orthopedics and Rheumatology Open Access Journal (OROAJ)}

Table 3B: Bivariate Analysis of the patient's high left hip acetabular residual angles post-surgery. $N=143$

\begin{tabular}{|c|c|c|c|c|}
\hline \multicolumn{5}{|c|}{ Left Hip Angle Residual } \\
\hline & $<=25$ degrees, $n=34$ & $>25$ degrees, $n=109$ & Test statistic & p-value \\
\hline \multicolumn{5}{|l|}{ Sex } \\
\hline Female & $32(94.1)$ & $91(83.5)$ & $\chi 2(1)=2.44$ & 0.119 \\
\hline Male & $2(5.9)$ & $18(16.5)$ & & \\
\hline $\begin{array}{c}\text { Age (months) at surgical } \\
\text { time }\end{array}$ & $7.79(1.50)$ & $7.50(1.7)$ & $t(141)=1$ & 0.329 \\
\hline \multicolumn{5}{|l|}{ Age group } \\
\hline$<=7$ months & $12(35.3)$ & $57(52.3)$ & $\chi 2(1)=2.99$ & 0.083 \\
\hline >7 Months & $22(64.7)$ & $52(47.7)$ & & \\
\hline \multicolumn{5}{|l|}{ Affected hip side } \\
\hline Unilateral-Left Hip Only & $10(29.4)$ & $54(49.5)$ & $\chi 2(1)=4.25$ & 0.039 \\
\hline Bilateral & $24(70.6)$ & $55(50.5)$ & & \\
\hline \multicolumn{5}{|l|}{$\begin{array}{c}\text { Received Pelvic Harness } \\
\text { therapy }\end{array}$} \\
\hline No & $9(26.5)$ & $30(27.5)$ & $\chi 2(1)=0.014$ & 0.904 \\
\hline Yes & $25(73.5)$ & $79(72.5)$ & & \\
\hline \multicolumn{5}{|l|}{ Required Tenotomy surgery } \\
\hline No & $11(32.4)$ & $42(38.5)$ & $x^{2}(1)=0.0 .42$ & 0.515 \\
\hline Yes & 23 (67.6) & $67(61.5)$ & & \\
\hline \multicolumn{5}{|l|}{$\begin{array}{l}\text { Final Success of CR docu- } \\
\text { mented by X-ray }\end{array}$} \\
\hline No & $2(5.9)$ & $3(2.8)$ & $\chi 2(1)=0.104$ & 0.747 \\
\hline Yes & $32(94.1)$ & $105(97.2)$ & & \\
\hline \multicolumn{5}{|l|}{$\begin{array}{l}\text { Final Left acetabular Index } \\
\text { (degrees), Mean (SD) }\end{array}$} \\
\hline $\begin{array}{l}\text { Follow up duration } \\
\text { (months), mean (SD) }\end{array}$ & $29.56(13.30)$ & $23.30(15.50)$ & $\mathrm{t}(63.3)=2.32$ & 0.024 \\
\hline
\end{tabular}

Table 4A: Multivariate Binary Logistic Regression Analysis of the Patients odds of having final High Right Hip Acetabular Residual. N=115

\begin{tabular}{|c|c|c|c|c|}
\hline \multirow{2}{*}{} & \multirow{2}{*}{$\begin{array}{c}\text { Multivariate adjusted } \\
\text { Odds Ratio }\end{array}$} & 95\% C.I.for Odds Ratio \\
\cline { 3 - 5 } & 1.383 & .415 & Upper & .598 \\
\hline Sex=Male & .494 & .205 & 1.194 & .117 \\
\hline Age at surgery time > & & & & \\
\hline Months & .456 & .187 & 1.109 & .083 \\
\hline Underwent Tenotomy & 1.037 & 1.007 & 1.067 & .015 \\
\hline Follow up months & .997 & .439 & 2.263 & .994 \\
\hline Underwent Salter surgery & 2.955 & 1.172 & 7.448 & .022 \\
\hline Has Unilateral affected right hip & .957 & & & .935 \\
\hline Constant & & & \\
\hline
\end{tabular}

Dependent variable $=$ Right acetabular index $>25$ (No/Yes). 


\section{Orthopedics and Rheumatology Open Access Journal (OROAJ)}

Table 4B: Multivariate Binary Logistic Regression Analysis of the Patients odds of having final High LEFT Hip Acetabular Residual. N=143.

\begin{tabular}{|c|c|c|c|c|}
\hline & Multivariate adjusted & \multicolumn{2}{|c|}{ 95\% C.I.for Odds Ratio } & Upper \\
\hline & Odds Ratio & Lower & 15.523 & .129 \\
\hline Sex= male & 3.309 & .705 & 1.546 & .333 \\
\hline Age at surgical time>7 months & .654 & .277 & 1.544 & .337 \\
\hline Underwent tenetomy & .659 & .281 & 1.005 & .102 \\
\hline Months of follow up & .974 & .945 & 1.872 & .631 \\
\hline Underwent salter surgery & .816 & .356 & 3.532 & .509 \\
\hline Underwent brace treatment & 1.375 & .535 & & $<0.001$ \\
\hline Constant & 8.176 & & & \\
\hline
\end{tabular}

We found that patients with unilateral right DDH were substantially more predictable for high acetabular index $(>25$ degrees) than those who had bilateral DDH ( $\mathrm{p}=0.010)$ according to the chi-squared test of independence. Moreover, the patients who had tenotomy were significantly less predictable for a high acetabular index $(\mathrm{p}=0.037)$. The unpaired samples t-test showed that the children who had high acetabular index (i.e., those with acetabular index $>25$ degrees) required significantly longer follow-up months $(M=28.62)$ on average than those who had measured low acetabular index $(M=21.88)(p=0.020)$. Our findings suggested that patients with unilateral left DDH were significantly less predictable for high acetabular index angle than the children who had bilateral DDH $(\mathrm{p}=0.039)$. Interestingly, the follow-up period for patients with high left side acetabular index was significantly lower (mean follow-up time $=23.30$ months) than patients with standard left acetabular index (mean follow-up time $=29.56$ months $)$ on average $(\mathrm{p}=0.024)$.

\section{Discussion}

DDH treatment can be conservative or surgical. If conservative treatment fails or the patient presented late, we perform close reduction under anesthesia with or without an adductor tenotomy. This procedure is followed by post reduction immobilization of the affected hip in a spica cast for twelve weeks $[1,3,4,6]$.
Although largely successful CR may lead to several complications, including AVN of the femoral head and loss of reduction. Even though osteonecrosis is one of the most concerning complications following CR [3,4,12-14], we have not included the evaluation incidence of AVN in this study as this needs prolonged followup. Some authors have suggested 10-12 years of follow-up to ascertain the true incidence of AVN, and others argued that follow-up beyond two years will not identify any additional cases of $\operatorname{AVN}[4,12,15,16]$.

Achieving and maintaining a concentric reduction of the hip is the ultimate treatment goal and is the primary stimulus of future acetabular growth and development [1,3]. Rates of failed initial reduction across the literature vary between $2 \%$ and $17 \%$, and the rates of loss of reduction vary from $0 \%$ to $18 \%$ [17-20] (Table 5). In this study, $88.1 \%$ of hips were successfully reduced on the initial attempt, with $4.5 \%$ failed CR at the latest follow-up. Our results fall within the lower half of the previously reported ranges, suggesting reasonable success rates may be achieved. MacEwen and Zionts [13] reported the outcomes in 51 dislocated hips in 42 children between 1 and 3 years of age at the time of reduction. Thirty-eight hips (75\%) were treated by traction prior to reduction, gentle $\mathrm{CR}$, and hip spica with or without adductor tenotomy. Thirteen hips (25\%) required an open reduction via anterior approach when stable CR could not be achieved.

Table 5: The rate of redislocation following closed reduction and spica cast immobilization reported by different researchers.

\begin{tabular}{|c|c|c|}
\hline Authors & Years \& Journal & Redislocation rate \\
\hline NH Kim [3] & 1990, Yonsei Med J & $7.7 \%(1 / 13)$ \\
\hline RH Quinn [4] & 1994, J Pediatr Orthop & $5.8 \%(3 / 52)$ \\
\hline N Yamada [5] & 2003, J Bone Joint Surg Br & $1.7 \%(1 / 58)$ \\
\hline R Pospischill [6] & 2012, Clin Orthop Relat Res & $17.4 \%(8 / 46)$ \\
\hline WN Sankar [7] & 2016, J Pediatr Orthop & $8.9 \%(7 / 79)$ \\
\hline A Bhaskar [8] & 2016, Indian J Orthop & $11.8 \%(2 / 17)$ \\
\hline
\end{tabular}

Residual dysplasia following CR is another concern [5,16,2122]. Since young patients with acetabular dysplasia are usually asymptomatic, the decision to undertake surgical correction through acetabulplasty during childhood depends more on radiological characteristics. Tonnis [11] \& Schwartz [12] have suggested that surgical correction of residual acetabular dysplasia should be performed when the acetabular index (AI) is $>25^{\circ}$. In this study, we have determined residual dysplasia by measuring the acetabular index. We have found that $68.5 \%$ of hips in this study had residual acetabular dysplasia at final follow- 
up. However, that rate will likely rise with continued followup. In comparison, the rates of residual dysplasia across the literature range from $57 \%$ to $100 \%$, with most published studies identifying a frequency of $35 \%$ [13-18]. This study has some limitations. First, longer follow-up may lead to different values for rates of acetabular dysplasia and further corrective surgery. Second, due to the large number of surgeons contributing to the database, there is considerable variation in treatment practices. However, we consider this heterogeneity a strength rather than a weakness in that it accurately reflects real-life practice. Third, our determined reference value for the acetabular index is only valid in symptomatic children. They can be used for diagnosis and treatment in these children but must be used in context with patient history and clinical findings.

\section{Conclusion}

CR and hip spica were able to achieve a stable and concentric reduction in most patients. However, this procedure is associated with a high rate of residual acetabular dysplasia. We recommend that the parents of such patients be counseled about the possibility of further surgery at a later stage.

\section{Compliance with Ethical Standards}

\section{Conflict of Interest}

The authors declare that they have no conflict interest.

\section{Informed consent}

This study is a retrospective study of patient's data, and an IRB approval was obtained, so formal consent is not required.

\section{References}

1. Guille JT, Pizzutillo PD, MacEwen GD (2000) Development dysplasia of the hip from birth to six months. J Am Acad Orthop Surg 8(4): 232-242.

2. Li Y, Guo Y, Li M, Zhou Q Liu Y, et al. (2018) Multi-center Pediatric Orthopedic Study Group of China. Acetabular index is the best predictor of late residual acetabular dysplasia after closed reduction in developmental dysplasia of the hip. Int Orthop 42(3): 631-640.

3. Peled E, Eidelman M, Katzman A, Bialik V (2008) Neonatal incidence of hip dysplasia: ten years of experience. Clin Orthop Relat Res 466(4): 771-775.

4. Kim NH, Park BM, Lee HM (1990) Congenital dislocation of the hip: a long-term follow-up in Korea. Yonsei Med J 31(2): 134-143.

5. Quinn RH, Renshaw TS, DeLuca PA (1994) Preliminary traction in the treatment of developmental dislocation of the hip. J Pediatr Orthop 14(5): 636-642.

6. Yamada N, Maeda S, Fujii G, Kita A, Funayama K, et al. (2003) Closed reduction of developmental dislocation of the hip by prolonged traction. J Bone Jt Surg Br 85(8): 1173-1177.

7. Pospischill R, Weninger J, Ganger R, Altenhuber J, Grill F (2011) Does open reduction of the developmental dislocated hip increase the risk of osteonecrosis?. Clin Orthop Relat Res 470(1): 250-260.

8. Sankar WN, Gornitzky AL, Clarke NM, Herrera-Soto JA, Kelley SP, et al (2019) Closed reduction for developmental dysplasia of the hip: earlyterm results from a prospective, multicenter cohort. J Pediatr Orthop 39(3): 111-118.

9. Barakat AS, Zein AB, Arafa AS, Azab MA, Reda W, et al. (2017) Closed reduction with or without adductor tenotomy for developmental dysplasia of the hip presenting at walking age. Curr Orthop Pract 28(2): 195-199.

10. Bhaskar A, Desai H, Jain G (2016) Risk factors for early redislocation after primary treatment of developmental dysplasia of the hip: Is there a protective infuence of the ossifc nucleus? Indian J Orthop 50(5): 479-485.

11. Tonnis D (1987) Congenital dysplasia and dislocation of the hip in children and adults. Berlin, Springer-Verlag, London, UK, pp. 80-83.

12. Schwartz DR (1965) Acetabular development after reduction of congenital dislocation of the hip. J Bone Joint Surg Am 47: 705-714.

13. Vitale MG, Skaggs DL (2001) Developmental dysplasia of the hip from six months to four years of age. J Am Acad Orthop Surg 9(6): 401-411.

14. Clarke N MP, Castaneda P (2012) Strategies to improve nonoperative childhood management. Orthop Clin North Am 43(3): 281-289.

15. Zionts LE, MacEwen GD (1986) Treatment of congenital dislocation of the hip in children between the ages of one and three years. J Bone Joint Surg Am 68(6): 829-846.

16. Orak MM, Onay T, Gumustas SA, Gursoy T, Muratli HH (2015) Is prematurity a risk factor for developmental dysplasia of the hip? : a prospective study. Bone Joint J 97-B(5): 716-720.

17. Wirth T, Stratmann L, Hinrichs F (2004) Evolution of late presenting developmental dysplasia of the hip and associated surgical procedures after 14 years of neonatal ultrasound screening. J Bone Joint Surg Br 86(4): 585-589.

18. Mulpuri K, Song KM, Goldberg MJ, Sevarino K (2015) Detection and nonoperative management of pediatric developmental dysplasia of the hip in infants up to six months of age. J Am Acad Orthop Surg 23(3): 202-205.

19. Omeroglu H, Kose N, Akceylan A (2016) Success of Pavlik harness treatment decreases in patients Z4 months and in ultrasonographically dislocated hips in developmental dysplasia of the hip. Clin Orthop Relat Res 474(5): 1146-1152.

20. Luhmann S, Bassett GS, Gordon JE, Schootman M, Schoenecker PL (2003) Reduction of a dislocation of the hip due to developmental dysplasia. Implications for the need for future surgery. J Bone Joint Surg Am 85(2): 239-243.

21. Schoenecker PL, Bitz M, Witeside LA (1978) The acute effect of position of immobilization on capital femoral epiphyseal blood flow. Aquantitative study using the hydrogen washout technique. J Bone Joint Surg Am 60(7): 899-904.

22. Zamzam MM, Kremli MK, Khoshhal KI, Abak AA, Bakarman KA, et al. (2008) Acetabular cartilaginous angle: a new method for predicting acetabular development in developmental dysplasia of the hip in children between 2 and 18 months of age. J Pediatr Orthop 28(5): 518-523. 
This work is licensed under Creative Commons Attribution 4.0 License DOI: 10.19080/OROAJ.2021.19.556012
Your next submission with Juniper Publishers will reach you the below assets

- Quality Editorial service

- Swift Peer Review

- Reprints availability

- E-prints Service

- Manuscript Podcast for convenient understanding

- Global attainment for your research

- Manuscript accessibility in different formats ( Pdf, E-pub, Full Text, Audio)

- Unceasing customer service

Track the below URL for one-step submission https://juniperpublishers.com/online-submission.php 